\title{
Editorial: Traditional Food Knowledge: New Wine Into Old Wineskins?
}

\author{
Andrea Pieroni ${ }^{1}$, Michele Filippo Fontefrancesco ${ }^{1 *}$ and Ina Vandebroek ${ }^{2}$ \\ ${ }^{1}$ University of Gastronomic Sciences, Bra, Italy, ${ }^{2}$ New York Botanical Garden, New York, NY, United States
}

Keywords: traditional food and beverages, traditional knowledge, traditional food knowledge, ethnobiology, social and cultural anthropology, sociocultural change

\section{Editorial on the Research Topic}

Traditional Food Knowledge: New Wine Into Old Wineskins?

The call for this Research Topic focused on Traditional Food Knowledge (TFK) and its potential for revitalization. Although over the past two decades studies of Traditional Knowledge have greatly increased according to the peer-reviewed literature, these have remained largely focused on ecological, botanical, and medical folk knowledge, while dedicating much less attention to knowledge about animals, foods or rituals. Moreover, while such studies have described mainly the use of biological organisms or systems and their ways of processing, they only have sparingly addressed their associated sociocultural values. Also, in the domain of TFK, field studies have unevenly looked at the processes through which TFK can be implemented in local, community-based programs (see articles published over the past decade in Journal of Ethnic Foods; Journal of Ethnobiology and Ethnomedicine; Journal of Ethnobiology; Economic Botany; Food, Culture \& Society). The current Research Topic offered scholars an opportunity to fill this gap, by exploring new strategies for local production based on the actualization of TFK, promoting locally-owned sustainable tourism and gastronomy with traditional products, and fostering collaborative inclusive platforms of producers, chefs, food activists, local institutions, consumers, and communities. Moreover, this Special Issue intended to invite scholars to look beyond an often-romanticized vision of TFK and to explore the ambiguities of its valorization, i.e., the conundrum generated by commoditization of local knowledge.

Four contributions in this Research Topic bring to the forefront the issue of knowledge erosion, its causes, and the potential for revitalization of TFK. Price et al. investigated the trajectories of food oppression experienced by Indigenous peoples in a contemporary context that have led to the marginalization of their traditional foodways, leading to their overall disempowerment. This discussion is furthered by Joseph and Turner who looked at the processes of erosion and revitalization of TFK among Indigenous peoples in Northwestern North America. While these authors pointed out the impact of Western colonization as a main factor in the loss of TFK, they framed the reappropriation of foods and food practices within an ongoing process of empowerment undertaken by Indigenous communities and supported by academic, governmental, and other allies. Moving the focus to the Sierra Norte de Madrid in Spain, Aceituno-Mata et al. considered the loss in the use of wild food plants and highlighted new trends of leisure and food consumption in Spanish society that are boosting the revival of this practice. Finally, Joseph and Voeks investigated changes in TFK among Indian immigrant women in Southern California, exploring the role of migration as the context for adaptation and transformation of TFK.

Three articles in this Research Topic expand the discussion by considering the link between TFK, environmental conservation, and community resilience. Campbell et al. looked at the 
Millbank region in Jamaica and showed the role of wild food harvesting as a crucial resource for communities to mitigate food insecurity and maintain the well-being of rural households. Similarly, Castagnetti et al., who undertook a study in Darchula in Far Western Nepal, looked at the interconnection between the community's farming and religious year circle and showed the importance of understanding religious practices to design and implement sustainable development policies for food sovereignty. Moreover, in the wake of growing recognition of Faroese Cuisine, Svanberg explored the role of animal fat in the traditional foodways of the islands. Facing the disappearance of TFK, he suggests that the future of Faroese cuisine lies in the maintenance and continuation of local knowledge about traditional ways to extract different types of animal fat and process it into locally made dishes.

Three other articles in this Research Topic consider the relationship between the revival of TFK and the socio-economic forces that (can) promote it. In this respect, Vandebroek et al. analyzed the continued sociocultural relevance of root tonics and their potential for sustainable development for the benefit of local artisanal producers. The value of these drinks as biocultural heritage is rooted in the country's deep cultural history since Transatlantic slavery and also shows their capacity to embody the cultural values of contemporary Jamaican society. Similary, Zocchi and Fontefrancesco explored the sociocultural causes of the revival of traditional products in the restaurant sector in Nakuru County, Kenya. They suggest that the recent revival of these products is associated with the economic and logistic factors of the sector and, above all, because these foods respond to the cultural needs of contemporary Kenyan society in terms of food safety. Finally, Fontefrancesco and Zocchi described the decline and revival of asparagus production in Mezzago, Italy, triggered by the organization of a local food festival, which shows the slippery divide between commodification of TFK and its revitalization through tourism.

Imagining the future of TFK studies, we propose that increasing attention to the actual (realized) or potential (envisioned) impacts of knowledge transformation highlighted in this Research Topic (erosion, revitalization, resilience, reappropriation, empowerment, and rural development) will help to expand the focus of studies in this field of ethnobiology. However, in order to build bridges, researchers and local communities should remain engaged in a long-term dialogue to address issues such as commodification and decolonization and co-create projects together. Ideally, these projects should not only be designed to satisfy intellectual curiosity, but also focus in non-fragmentary ways on the multidimensional values of TFK as an immaterial cultural good with spiritual agency that has been co-opted as a policy tool for improving food and nutrition security and public health.

\section{AUTHOR CONTRIBUTIONS}

All authors listed have made a substantial, direct and intellectual contribution to the work, and approved it for publication.

Conflict of Interest: The authors declare that the research was conducted in the absence of any commercial or financial relationships that could be construed as a potential conflict of interest.

Copyright (c) 2021 Pieroni, Fontefrancesco and Vandebroek. This is an open-access article distributed under the terms of the Creative Commons Attribution License (CC $B Y)$. The use, distribution or reproduction in other forums is permitted, provided the original author(s) and the copyright owner(s) are credited and that the original publication in this journal is cited, in accordance with accepted academic practice. No use, distribution or reproduction is permitted which does not comply with these terms. 